\title{
INFLUENCE OF ELECTROPHORETIC DEPOSITION PARAMETERS ON PORE SIZE DISTRIBUTION OF DOPED NANO ALUMINA PLATES
}

\author{
"MOSTAFA MILANI*, SEYED MOHAMMAD ZAHRAEE*, SEYED MOHAMMAD MIRKAZEMI** \\ *Advanced Materials \& Renewable Energies Department, \\ Iranian Research organization for science and technology, Tehran, Iran \\ **School of Metallurgy and Materials Engineering, \\ Iran University of Science and Technology, Tehran, Iran \\ "E-mail: m_milany2000@yahoo.com
}

Submitted May 18, 2016; accepted July 24, 2016

\begin{abstract}
Keywords: $\mathrm{EPD}, \mathrm{Al}_{2} \mathrm{O}_{3}$, Dopant, Porosity, Thick layer
Doped nano alumina powders were successfully deposited as a thick film by electrophoretic deposition (EPD). A mixture of ethanol, cation salts of alumina dopants and iodine was used for dispersion system. Mg-Y-La-and Ce-salts add to ethanol and deposited with alumina powders on to substrate. The effects of suspension power loading, deposition time, electrode distance and applied potential simultaneously on density, pore size distribution and cell current density of alumina nanoparticles were examined. The weight of deposition increased with time and voltage increased and electrode distance decreased. In all applied voltages in higher suspension concentration, weight of deposition are sufficiently high but the density of the film are clearly better in low and high voltages than medium voltage. In constant suspension concentration with increasing in applied voltage, deposition rate increased and current decreased faster than medium voltage, which limits the homogeneous deposition forming and decreased density. Low applied voltages provided better pore size distribution and narrow and steep slope in middle of pore size distribution plot. High density samples with best pore size distribution achieved in lower rate deposition and assisted to better densification at sintering step in doped alumina plates.
\end{abstract}

\section{INTRODUCTION}

Alumina ceramics have been studied most intensively and are widely used in structural applications because of a wide variety of applications and excellent mechanical properties [?]. alumina use in ceramic-based orthodontic appliances [1], transparent ceramics [2], cutting tools [3], armors [4] and etc.. The usefulness of alumina derives from a variety of its properties. It has a high chemical stability leading to applications as biomedical implants. The hardness, strength, melting point $\left(2054^{\circ} \mathrm{C}\right)$ and abrasion resistance of alumina are among the highest for oxides. For high density alumina producing, both grain size and porosity, with a narrow distribution of nanometric pores, have to be carefully controlled. To do so, two strategies were combined: shaping the powders by colloidal shaping methods and doping alumina with metal oxides (ppm range). With good selection of method and variables fine-grained materials with high density and superior properties achieved [5].

Whit recently shaping methods high strength alumina now is possible with grain sizes less than $1 \mu \mathrm{m}$ at a relative density of more than $98.5 \%$ and with a high degree of pore homogeneity which is, possibly, even more important [6]. However, reliability, processing and cost has been a challenge to producing high density alumina still now. high production rates and the formation of a homogeneous compact are generally desirable.

During the past several years, much colloidal shaping methods have been made in producing ceramics. There are several colloidal forming methods, such as slip casting, gel casting and electrophoretic deposition (EPD). Unfortunately, however, scale ability of these techniques into fully dense, bulk products has proven to be difficult. In the EPD method, dispersed particles in a water base or organic liquid are made to move toward a particular electrode in the presence of an electric field. In this colloidal processing technique, non-aqueous suspensions often used in order to avoid the hydrolysis of water at the electrodes. EPD combining the advantages of the colloidal processing and the electric field assisted processing of ceramics [7]. Bredol et al. reported electrophoretic deposition and hot press sintering of transparent and high density alumina, yttria, yttrium aluminium garnet and lutetium aluminium garnet [8]. No sintering aids used in their suspension preparation.

The amount of porosity in green state is dependent on the order of particles arrangement and rearrangement in deposit during EPD. Furthermore, pore size distribution, that is essential for improving the density of sintered sample, can be influenced by EPD parameters. 
On the other hand, for full densification, commonly rare-earth and/or alkaline earth oxides are often added as grain growth inhibitors, in the fabrication of high density ceramics []. Alumina generally densified with the use of mono or trivalent cations, the most common being $\mathrm{MgO}, \mathrm{Y}_{2} \mathrm{O}_{3}, \mathrm{La}_{2} \mathrm{O}_{3}$ and $\mathrm{ZrO}_{2}$. Recently Braunt et al. reported production of a transparent alumina by means of EPD and HIP [9]. They studied the influence of $\mathrm{MgO}$ and $\mathrm{ZrO}_{2}$ dopings on the densification and microstructure development at different dopant levels, and sintering aids added in crystalline structure, i.e. powder form. They represented $250 \mathrm{ppm}$ and $450 \mathrm{ppm}$ are the optimal doping level for $\mathrm{MgO}$ and $\mathrm{ZrO}_{2}$, respectively, to the highest density in the final sintered alumina samples.

Recently combination of electrophoretic deposition and sol gel technique used to fabricate homogeneous, crack-free and thicker samples. Castro et al. deposited a $\mathrm{SiO}_{2}$ coating from nano-particulate silica sol/gel suspensions [10]. Preparation of a suspension by means of a sol gel solvent implemented by Zhang et al. they electrophoretically deposited $\mathrm{SiC}$ and $\mathrm{ZrO}_{2}$ powders from sol gel base suspension to add alumina ions as an additive [11].

Influence of electrophoretic parameters in yield or rate of deposition were very investigated in recent years []. On the other hand density of deposition was studied in some researches [12-15]. Ji et al [16] found that the packing density of wet deposits decreases with the increase in the deposition voltage and time. According to Bernardo et al. no appreciable differences were observed in density in different deposition rate [12] in spite of Krüger et al which believing that in lower deposition rate the formation of a close-packed structure are more optimized [17]. This work is focused on $\alpha-\mathrm{Al}_{2} \mathrm{O}_{3}$, and small amount of sintering additives $\left(\mathrm{MgO}, \mathrm{Y}_{2} \mathrm{O}_{3}, \mathrm{La}_{2} \mathrm{O}_{3}\right.$ and $\mathrm{CeO}_{2}$ ) were used as grain growth inhibitors. These additives are essential to achieve a very dense sintered body with a fine-grained microstructure [?]. On the other hand effect of suspension concentration, applied potential, deposition time and electrode distance on the green body density, efficiency, weight of deposit and cell current are presented. As well as discussed above, the sintered density isn't also dependent on the green body density. In order to investigate the effect of electrophoretic variables on the sintered density, pore size distribution of electrophoretic deposited samples was examined in selected suspensions.

\section{EXPERIMENTAL}

\section{Suspension preparation and deposition process}

The starting powder used is commercially available alpha alumina powder, with a specific surface area of $19.95 \mathrm{~m}^{2} \cdot \mathrm{g}^{-1}$ and a mean particle size of $80 \mathrm{~nm}\left(\mathrm{Al}_{2} \mathrm{O}_{3}\right.$, alpha, $99 \%, 80 \mathrm{~nm}$, US3008, US-Nano, US). Impurity analysis by the ICP-OES method showed the major impurities in the powder were as follows (ppm): $\mathrm{Mg}(11)$ $\mathrm{K}$ (20), Ga (40), Na (10), Fe (10), Y (11), Zn (18), La (2), $\mathrm{Ce}(5)$ and $\mathrm{Ca}(40)$.

Medium-solids-loading alcohol based slurries were prepared with the raw powder and iodine and as a dispersant. To dope the powder and prepare the suspensions for EPD, alumina powder was dispersed in ultra-pure ethanol $\left(\mathrm{C}_{2} \mathrm{H}_{5} \mathrm{OH}\right.$, Merck Millipore, $99.6 \%$ ) before addition of the desired amounts of iodine (Merck Millipore, $99 \%$ ) solution as a dispersant. After an ultrasonic bath (UB) treatment of $15 \mathrm{~min}$, $\mathrm{Mg}^{2+}, \mathrm{Y}^{3+}, \mathrm{La}^{3+}$ and $\mathrm{Ce}^{4+}$ ethanolic solutions $\left(\mathrm{MgCl}_{2}\right.$, $\mathrm{YCl}_{3}, \mathrm{LaCl}_{3}$ and $\mathrm{Ce}\left(\mathrm{CH}_{3} \mathrm{CO}_{2}\right)_{3}$, respectively, Sigma Aldrich, $99.99 \%$, USA) were added. The final total dopant level was $1050 \mathrm{ppm}$ total cationic ratio. The final slurries with an $\mathrm{pH}$ around 6 to 7 were stirred and UB treated for another $15 \mathrm{~min}$ before the electrophoretic deposition. Iodine produce $\mathrm{I}^{-}$and $\mathrm{OH}^{-}$ions in ethanol as solved. The percentage of dispersant to the alumina powder was approximately $400 \mathrm{wt} \% \% \mathrm{ppm}$, which is the lowest possible percentage for suspension to minimize sedimentation during electrophoretic deposition is completed. The cation dopant salts gives enough ions to the suspension for suspension stability and the iodine consolidates the powders to maintain in the suspension.

The alumina samples were deposited on stainless steel substrates $(50 \mathrm{~mm} \times 40 \mathrm{~mm} \times 2 \mathrm{~mm})$ by immersing the substrate in the alumina suspensions, as contained in a PTFE cell (inner dimensions; $44 \mathrm{~mm} \times 40 \mathrm{~mm} \times$ $50 \mathrm{~mm}$ ) and applying a voltage differential between the substrate and the EPD cell counter (Ti-6Al-4V) using a regulated direct current power supply. The electrodes were set parallel to each other and immersed into the suspension kept at a constant temperature during EPD, and were cleaned with dipping in $1 \mathrm{M} \mathrm{HNO}_{3}$ acid, rinsed with deionized water and acetone before use. The stainless steel electrode, after deposition, was carefully removed from the colloidal suspension and the deposits were allowed to dry at room temperature for $24 \mathrm{~h}$. The deposits were then weighed to determine the yield by Sartorius balance equipment (US).

Wight of deposit, initial current (mA), Final current $(\mathrm{mA})$, Current drop $(\mathrm{mA})$, Density $\left(\mathrm{g} \cdot \mathrm{cm}^{-3}\right)$ and Efficiency (i.e. weight of deposit divided by weight of powder in suspension) (present) at two separation electrode distances (1 and $2 \mathrm{~cm}$ ) was investigated by changing deposition voltage $(50,60$ and $70 \mathrm{~V})$, deposition time (250, 350 and $450 \mathrm{~s})$ and weight of alumina in suspension (10, 15 and $20 \mathrm{~g} / 100 \mathrm{ml}$ ethanol). RSM design matrix was used to modelling experiment. Experiment model sketched in Figure 1.

These different samples are referred to as $\mathrm{W}_{0}$-E-t-d as a XX_XX_XX_X number, to indicate the experiment condition as well as the suspension concentration $\left(W_{0}=\right.$ initial alumina powder in suspension $(\mathrm{g}), E=$ applied potential $(\mathrm{V}), t=$ deposition time (s) divided by 10 and $d=$ electrode separation $(\mathrm{cm})$; all were in three level for all two separation distance). 


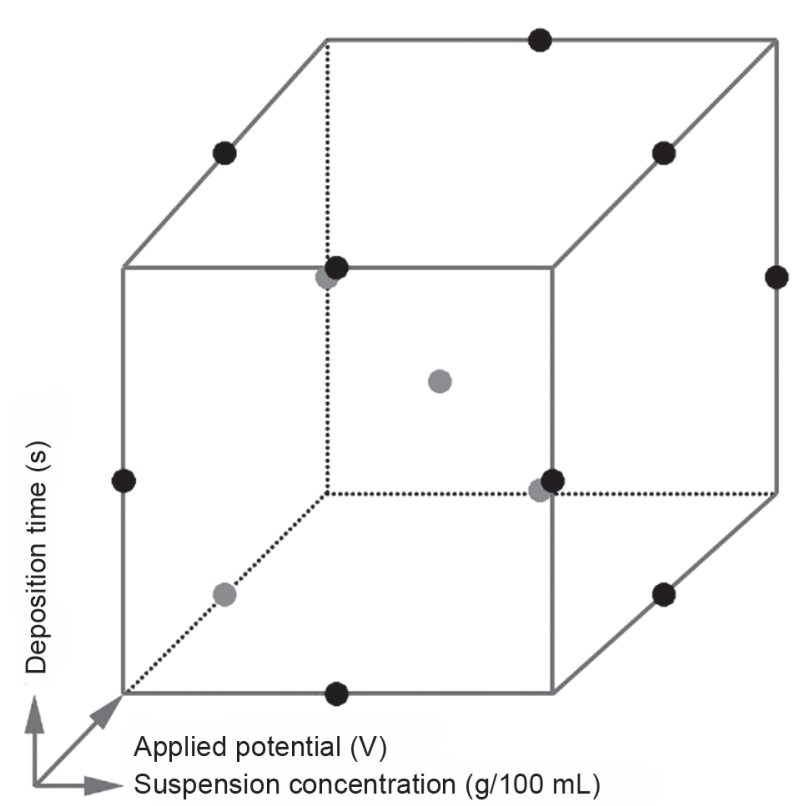

Figure 1. Design matrix for experiments repeated in two electrode distance.

increasing rate, $1^{\circ} \mathrm{C} \cdot \mathrm{min}^{-1}$, from ambient temperature to $800^{\circ} \mathrm{C}$, and this was followed by the 60 min dwell time. After it, the green body densities were determined by Archimedes method with deionized water (three measurements were made for each sample), using Sartorius YDK01 density determination kit (Sartorius, Germany) equipment (three measurements were made for each sample). Then, the relative density, $\mathrm{D}$, is obtained using a theoretical volume mass of alumina of $3.987 \mathrm{~g} \cdot \mathrm{cm}^{-3}$. The porosity distribution was evaluated by measuring the porosity using a high-pressure mercury intrusion porosimeter Micromeritics AutoPore IV 9500 (Micromeritics, Australia).

Investigation of influence of pore size distribution, density and weight of deposit on sintered density followed by sintering of green bodies in $1450^{\circ} \mathrm{C}$ for $2 \mathrm{~h}$. heating rate was $5^{\circ} \mathrm{C} \cdot \mathrm{min}^{-1}$ and samples were cooled in furnace.

The microstructure of the fracture surface of samples was observed by scanning electron microscopy (SEM, JSM-6510, JEOL, Japan), equipped with EDS.

\section{RESULTS AND DISCUSSION}

Weight of deposit $(\mathrm{g})$, Density $\left(\mathrm{g} \cdot \mathrm{cm}^{-3}\right)$, Efficiency $(\%)$, Initial Current (mA), Final Current (mA), and Current Drop (mA) were investigated in all samples (Table 1). All symbols elucidation and Maximum, minimum and average values were collected in Table 2. ve a necessary strength for porosimetry and measuring density. To avoid large numbers of pores and cracks, the calcination process was carried out using the low All symbols explain in Table 2.

\begin{tabular}{|c|c|c|c|c|c|c|c|c|c|c|}
\hline Code & A & B & $\mathrm{C}$ & $\mathrm{D}$ & Y1 & Y2 & Y3 & Y4 & Y5 & Y6 \\
\hline 1050351 & 10 & 50 & 350 & 1 & 1.6808 & 16.81 & 34 & 6.35 & 3.00 & 3.36 \\
\hline 1050352 & 10 & 50 & 350 & 2 & 1.5550 & 13.33 & 36 & 3.38 & 2.66 & 0.72 \\
\hline 1060251 & 10 & 60 & 250 & 1 & 2.7594 & 27.59 & 34 & 9.50 & 5.08 & 4.42 \\
\hline 1060252 & 10 & 60 & 250 & 2 & $1.2940 *$ & 13.39 & 34 & 3.34 & 2.83 & $0.51 *$ \\
\hline 1060451 & 10 & 60 & 450 & 1 & 3.1385 & 29.85 & 33 & 6.16 & 2.95 & 3.20 \\
\hline 1060452 & 10 & 60 & 450 & 2 & 2.5625 & 25.13 & 34 & 5.31 & 3.58 & 1.73 \\
\hline 1070351 & 10 & 70 & 350 & 1 & 2.8618 & 28.62 & 38 & 8.66 & 3.96 & 4.70 \\
\hline 1070352 & 10 & 70 & 350 & 2 & 2.4422 & 21.05 & $39 * *$ & 6.33 & 4.11 & 2.22 \\
\hline 1550251 & 15 & 50 & 250 & 1 & 2.7333 & 18.22 & 34 & 5.09 & 2.63 & 2.46 \\
\hline 1550252 & 15 & 50 & 250 & 2 & 1.9426 & $12.95 *$ & 36 & 3.74 & 2.77 & 0.98 \\
\hline 1550451 & 15 & 50 & 450 & 1 & 3.8760 & 25.84 & 33 & 7.30 & 2.57 & 4.73 \\
\hline 1550452 & 15 & 50 & 450 & 2 & 2.8298 & 18.87 & 33 & $3.25 *$ & $2.11 *$ & 1.14 \\
\hline 1560351 & 15 & 60 & 350 & 1 & 4.3834 & 29.22 & $32 *$ & $12.52 * *$ & 3.54 & $8.98 * *$ \\
\hline 1560352 & 15 & 60 & 350 & 2 & 3.2495 & 21.66 & 36 & 3.69 & 2.81 & 0.88 \\
\hline 1570251 & 15 & 70 & 250 & 1 & 3.6534 & 24.36 & 33 & 12.31 & $5.77 * *$ & 6.54 \\
\hline 1570252 & 15 & 70 & 250 & 2 & 2.3812 & 15.87 & 33 & 3.62 & 2.88 & 0.74 \\
\hline 1570451 & 15 & 70 & 450 & 1 & 5.2076 & $34.72 * *$ & 33 & 11.48 & 4.03 & 7.45 \\
\hline 1570452 & 15 & 70 & 450 & 2 & 4.0918 & 27.28 & 35 & 4.74 & 2.78 & 1.96 \\
\hline 2050351 & 20 & 50 & 350 & 1 & 4.1268 & 20.63 & 37 & 5.59 & 3.04 & 2.55 \\
\hline 2050352 & 20 & 50 & 350 & 2 & 3.4129 & 17.06 & 34 & 4.54 & 2.85 & 1.69 \\
\hline 2060251 & 20 & 60 & 250 & 1 & 4.1930 & 20.97 & 34 & 9.37 & 4.15 & 5.22 \\
\hline 2060252 & 20 & 60 & 250 & 2 & 2.8791 & 14.40 & 34 & 4.57 & 3.17 & 1.40 \\
\hline 2060451 & 20 & 60 & 450 & 1 & $6.3585 * *$ & 31.79 & 33 & 6.94 & 3.33 & 3.60 \\
\hline 2060452 & 20 & 60 & 450 & 2 & 4.8578 & 24.29 & 34 & 3.90 & 2.49 & 1.42 \\
\hline 2070351 & 20 & 70 & 350 & 1 & 4.0886 & 20.44 & 37 & 9.17 & 4.15 & 5.02 \\
\hline 2070352 & 20 & 70 & 350 & 2 & 4.6479 & 23.24 & 37 & 5.49 & 3.21 & 2.27 \\
\hline
\end{tabular}

* Minimum value, ** Maximum value 
Milani M., Zahraee S. M., Mirkazemi S. M.

Table 2. Independent variables and their levels in the experimental design.

\begin{tabular}{clccc}
\hline \multirow{2}{*}{ Symbol } & Factors & \multicolumn{3}{c}{ Levels } \\
\cline { 3 - 5 } & & Max. & Ave. & Min. \\
\hline A & Suspension concentration $(\mathrm{g} / 100 \mathrm{ml})$ & 10 & 15 & 20 \\
B & Applied potential $(\mathrm{V})$ & 50 & 60 & 70 \\
C & Deposition time $(\mathrm{s})$ & 250 & 350 & 450 \\
D & Electrode distance & 1 & - & 2 \\
Y1 & Weight of deposition $(\mathrm{g})$ & 1.2940 & 3.3541 & 6.3585 \\
Y2 & Efficiency $(\%)$ & 21.95 & 22.22 & 34.72 \\
Y3 & Density $\left(\mathrm{g} \cdot \mathrm{cm}^{-3}\right)$ & 32 & 34.62 & 39 \\
Y4 & Initial current $(\mathrm{mA})$ & 3.25 & 6.40 & 12.52 \\
Y5 & Final current $(\mathrm{mA})$ & 2.11 & 3.33 & 5.77 \\
Y6 & Current drop $(\mathrm{mA})$ & 0.51 & 3.07 & 8.98 \\
\hline
\end{tabular}

Weight, density and efficiency

Weight of deposit had a lower, average and upper value of $1.2940,3.3541$ and $6.3585 \mathrm{~g}$ respectively (Table 1). If divided the values of weight of deposited to 4 range, more of samples were between 2.5 to 4 g. Nineteen of samples had weight between 2.5 to $5.5 \mathrm{~g}$. These samples are between the samples had high deposition voltage, high concentration and low electrode distance $(1 \mathrm{~cm})$. Analysis indicated that the applied potential and suspension concentration have a high significant positive effect on the deposition weight, while deposition time has a moderate effect on the weight. According to Hamaker model weight of deposit had direct relationship with applied potential, suspension concentration and deposition time and reverse with electrode distance [18]. In Zhang et al. equation, however, weight of deposit increased exponentially with deposition time and applied potential. Although deposition weight increased with an increase in suspension concentration in both equation. According to observations of these research increase in yield was nonlinear with respect to this parameters. The presence of higher concentrations alumina powders prepared more particles for deposition but may prevent from the diffusion of particles in the suspension and deposition of it and thereby decreasing the deposited weight. On the other hand concentrated suspensions have more viscosity, provide lower particle mobility. Applying of higher electric field, although move the particles faster and reach more of them to deposited electrode but in high electric fields turbulence of suspension, can pull up previously deposited particles. It seems Zhang et al. equation in thicker deposition have better prediction because of considering viscosity in exponential phrase. Maximum yield can be achieved (i) at applied potential between 60 to $70 \mathrm{~V}$ with longer deposition times. This parameters have about equal effect in both electrode separation although in $2 \mathrm{~cm}$ electrode distance weight of deposit decreased than $1 \mathrm{~cm}$ distance.

Maximum Efficiency of the process, i.e. weight of deposited powder divided by weight of added powder to suspension, was $34.72 \%$. Minimum and average efficiency also were 12.95 and $22.21 \%$ respectively. Half of samples have lower efficiency than average (Figure 2). All of them except 1550452 deposited in 250 and $350 \mathrm{~s}$. this indicate that deposition time can increase efficiency. Efficiency can be increased in higher applied potential and lower electrode separation in critical deposition time and suspension concentration. Only two sample have higher than $30 \%$ efficiency, 2060451 and 1570451.

According to Table 1 green body density of the asdeposited alumina powders ranged from 32 to $39 \%$ and average density placed at $34.6 \% .17$ sample have 32 to $34 \%$ density and only 1 sample densified to higher than $38 \%$ (1070352). All samples that could densified to 37 and higher deposited in $350 \mathrm{~s}$.

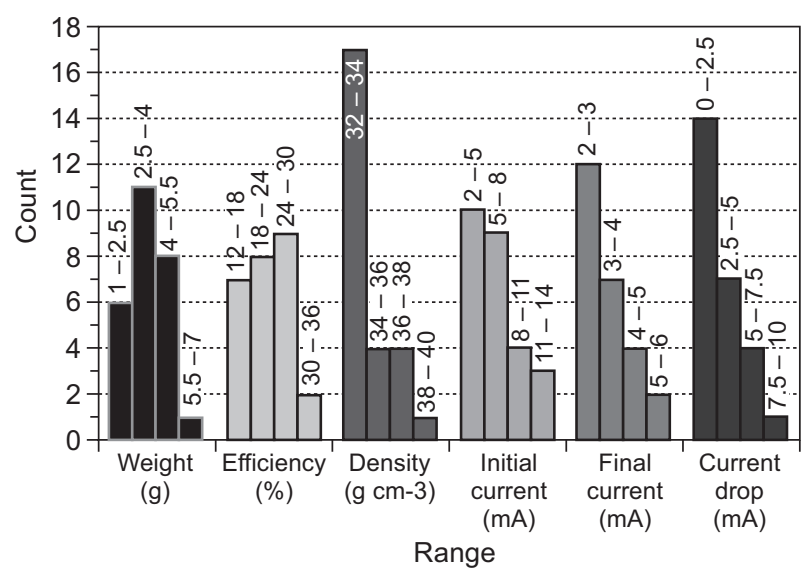

Figure 2. Response range in weight, efficiency, density, initial current, final current and current drop.

\section{Effect of process variables on current}

In the measured responses from Table 1, initial current, final current and difference between them (mA) indicated the significance changes according to process parameters. 
Initial current changed from 12.52 to $3.25 \mathrm{~mA}$. To analyze initial current density it must be remove deposition time from the variables. In this new conditions applied potential and electrode separation have a significant effect on the initial current. In higher applied potential current can be increased according to ohm's low in constant resistivity. Final current of the electrophoretic cell ranged from 5.77 to $2.11 \mathrm{~mA}$. $0.51 \mathrm{~mA}$ to $8.98 \mathrm{~mA}$ was current drop amplitude.

When look at corresponding samples of above mentioned values, first remarkable note is 1550452 have lower initial and final current. This indicate that $50 \mathrm{~V}$ applied potential in $2 \mathrm{~cm}$ electrode distance is not sufficient to deposit particles effectively in $450 \mathrm{~s}$ deposition time. In this sample only $18.87 \%$ of alumina particles deposited. Another note must be mentioned is occurring of maximum initial current and current drop in one sample i.e. 1560351. When electrode distance fixed to $1 \mathrm{~cm}$ moderate applied potential and suspension concentration $(60 \mathrm{~V}$ and $15 \mathrm{~g})$ create sufficient forces and viscosity (particle mobility) for particle deposition. Efficiency value of $29.22 \%$ implies that most of particles can deposit if sufficient time considered.

\section{Pore size distribution analysis}

Figure 3 compares the pore size evolution of bodies prepared by (i) $10 \mathrm{~g} / 100 \mathrm{ml}$ suspension, $70 \mathrm{~V}$ electric field in $350 \mathrm{~s}$ and electrode distance of $2 \mathrm{~cm}$, i.e. 1070352, (ii) $15 \mathrm{~g}, 60 \mathrm{~V}, 350 \mathrm{~s}$ and $1 \mathrm{~cm}$ (1560351) (iii) $20 \mathrm{~g}, 50 \mathrm{~V}$, $350 \mathrm{~s}$ and $1 \mathrm{~cm}$ and (iv) $20 \mathrm{~g}, 70 \mathrm{~V} 350 \mathrm{~s}$ and $1 \mathrm{~cm}$. In this samples, typical green densities (Table 1) were $39-33 \%$ of the theoretical value after equal calcination at $800^{\circ} \mathrm{C}$ (on beginning neck formation defined by Coble [19] as the initial state of solid state sintering) and with equal deposition time (350 s). For best comparison, this figure provides relative pore distributions with all curves

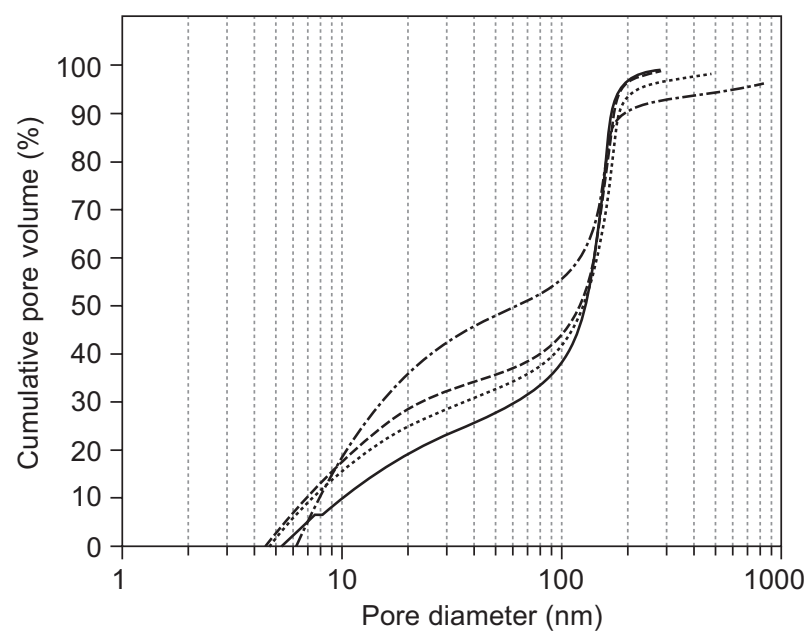

Figure 3. Cumulative pore volume vs pore diameter between 4 to $1000 \mathrm{~nm} .1070352$ (Solid line), 1560351 (dotted line), 2050351 (dashed line) and 2070351 (dot-dashed line). After burn-out of organic additives at $800^{\circ} \mathrm{C}$. running from 0 to 100 relative percents independent of the total absolute porosities that are given as a parameter. The lower bound of recorded pore sizes was $5 \mathrm{~nm}$, and an upper bound of $1000 \mathrm{~nm}$ was considered as a limit between real pores and larger defects, which were excluded from the pore size evaluation.

As a first result of Figure 3, pore size distribution of electrophoretic deposited bodies is sensitive to process parameters, and it is one of the consequences that a high density samples is rather difficult to produce (note, however, that with Table 1 the deposition weight is only slightly affected). It was be shown that the ceramics prepared by the three of four approaches all exhibit similar average pore sizes of about $130 \mathrm{~nm}$, and left over have about $90 \mathrm{~nm}$. The pore size distributions do not change substantially between the 1560351 and 2050351 .

Comparing the influences of processing, differences in the pore size distributions are manifested by two issues: the existence of larger pores and the slopes of the main bodies of the distributions: (1) all microstructures exhibit a tail of larger pores (larger than $180 \mathrm{~nm}$ ). Lower suspension concentration and higher electrode distance eliminates these larger pores. However, the slope at the center of the pore size distribution is still the same as observed for higher concentration and lower electrode distances (2070351). Lower applied potential (2050351) does not only provide green bodies without larger pores, i.e. shorter tail after $180 \mathrm{~nm}$, these microstructures also exhibit the smallest total width in the center of distribution plot and the slowest slope at the pore size distribution between 10 to $100 \mathrm{~nm}$, similarly well as observed in 1070352. By decreasing in suspension concentration and increasing in applied potential than 2050351 i.e. 1560351 tail of pore size distribution plot increased while overview of plot are same.

To summarize results between weight, efficiency, density and pore size, 1070352 exhibited low deposition weight, high density and low efficiency simultaneous with better pore distribution (solid line). In 2070351 sample, although deposition weight and density have higher values but efficiency decreased and pore size distributions have wide width and sample have inhomogeneous particle coordination.

According to the mechanisms that dictate the packing of the particles during EPD a higher packing density might be expected in lower deposition rate which may enable the particles to arrange themshelves at more optimized positions for the formation of a close-packed structure $[12,17]$. This mechanism could be represented for better pore size distribution. When deposition rate decreased, optimized deposition lead to better distribution in particles and simultaneously pores.

Homogeneity and morphology of the deposits was investigated by Bernardo et al. they found that, no appreciable differences were observed in the packing of the particles of the deposits with similar masses obtained from the different suspensions in spite of the different 
Milani M., Zahraee S. M., Mirkazemi S. M.

deposition rates in PZT films [12]. In other investigation Farrokhi-Rad et al. showed that the wet density of titania nano particles increases with deposition time although attains a plateau at longer times [15]. Although these investigations are considerable but higher deposit thickness in these works are 40 to $50 \mu \mathrm{m}$ while lower thickness obtained here was $775 \mu \mathrm{m}$ after calcination in $800^{\circ} \mathrm{C}$ (by SEM image measurement).

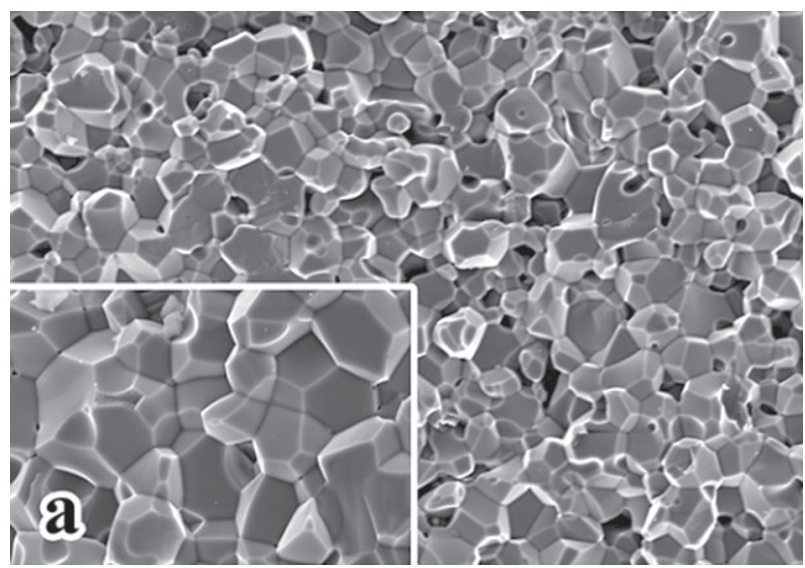

a) 1570251 conditions

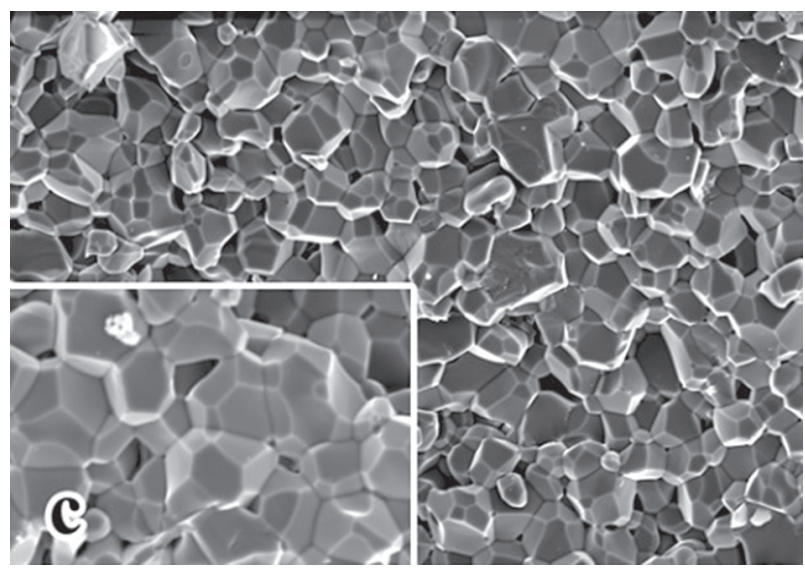

c) 1560351 conditions

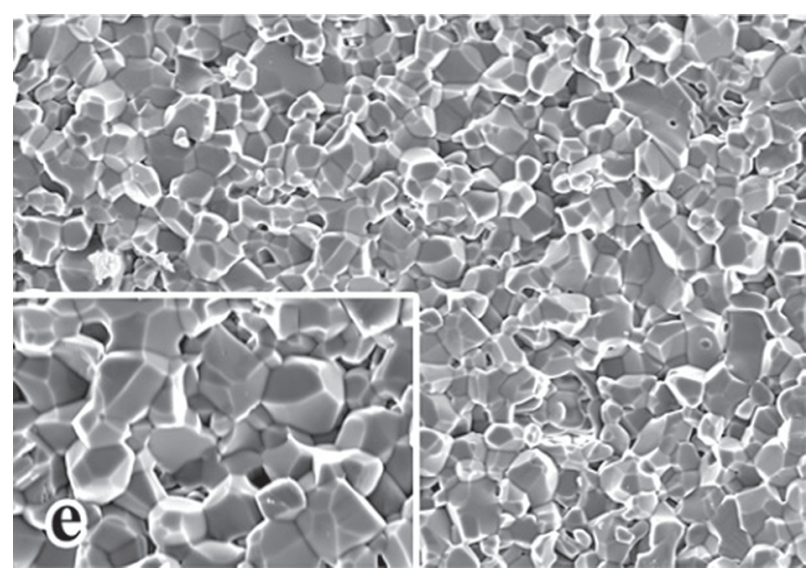

e) 1060252 conditions
Sintering and characterization of deposits

Homogeneity and morphology of he deposits

In order to study the effect of the four variables on the morphology and microstructure of the obtained layers, layers prepared from the electrodes with a different weight

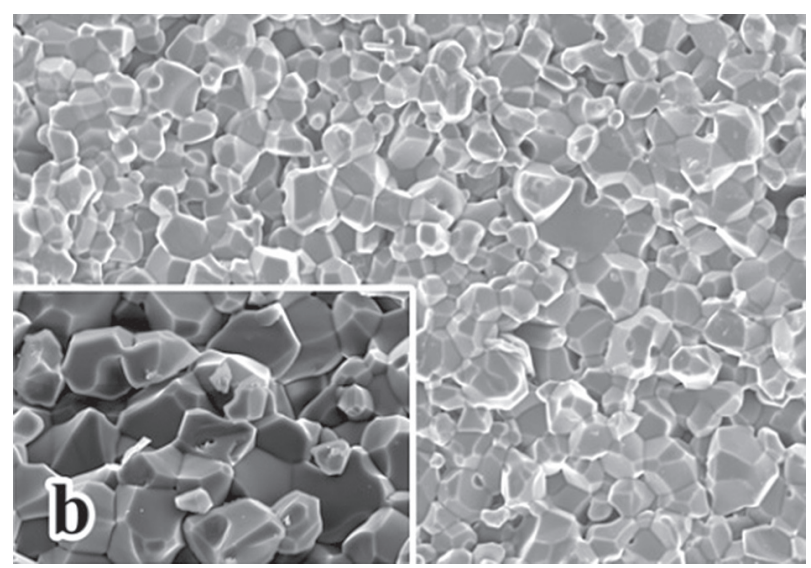

b) 1070352 conditions

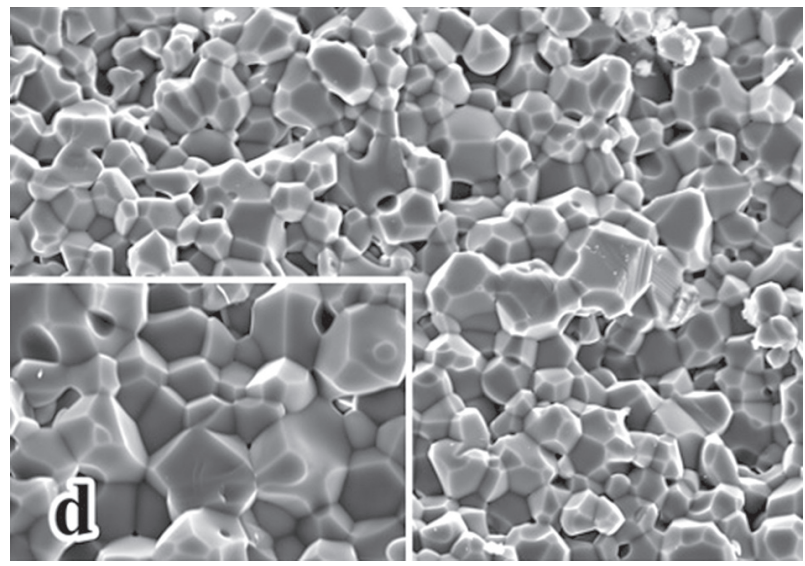

d) 2070351 conditions

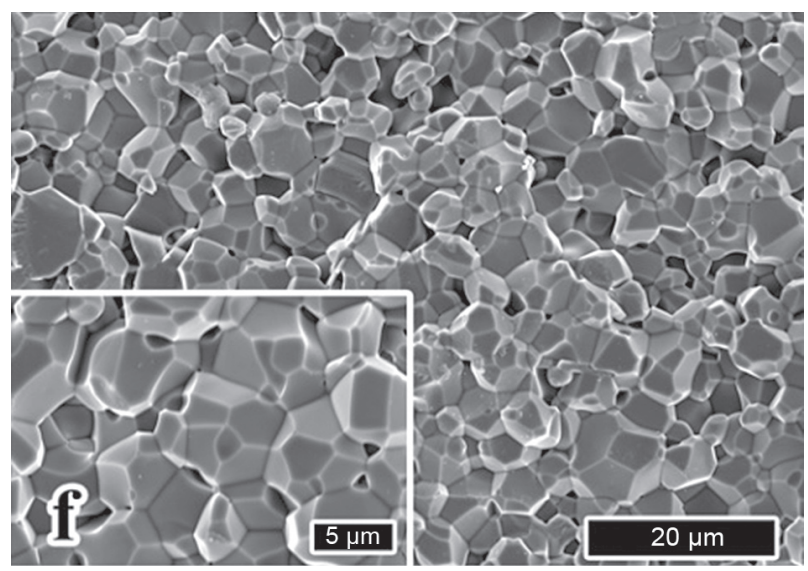

f) 2060451 conditions

Figure 2. SEM micrographs of the fracture surface of sintered layers obtained from the 1570251 (a), 1070352 (b), 1560351 (c), 2070351 (d), 1060252 (e) and 2060451 (f) conditions. High and low magnification displayed. 
and density were selected. This means that attractive samples in previous investigations, were selected. Scanning electron micrographs of the fracture surfaces of sintered samples prepared under different conditions are shown in Figure 4. A semi homogeneous packing of the particles is observed for all samples. According to the pore size distribution and other responses discussed above the packing of the particles might be expected for the 1070352 sample due to their lower deposition rate and better pore size distribution. Figure $4 \mathrm{~b}$ represented micrograph of this sample. For further investigation, the fracture cross-section surface of the 1560351 sample were also analyzed (Figure 4c). Because of minimum density and nearly high deposition rate of this sample

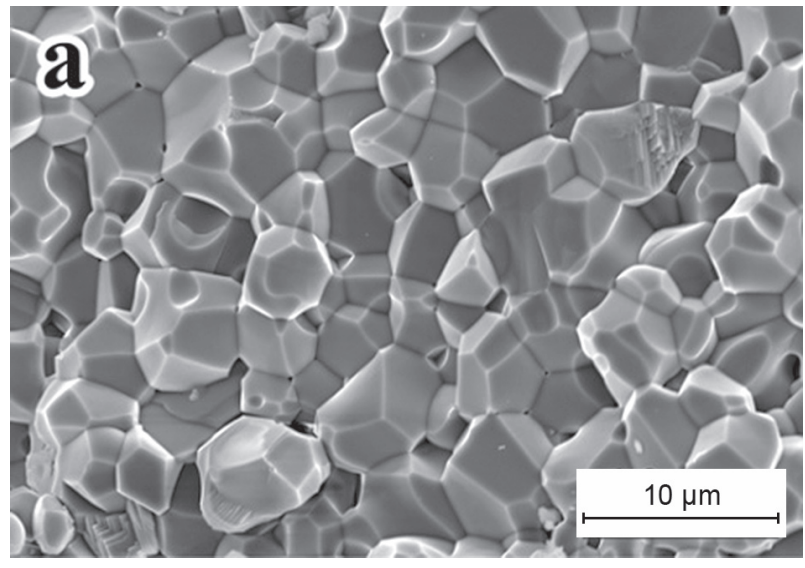

a) after sintering

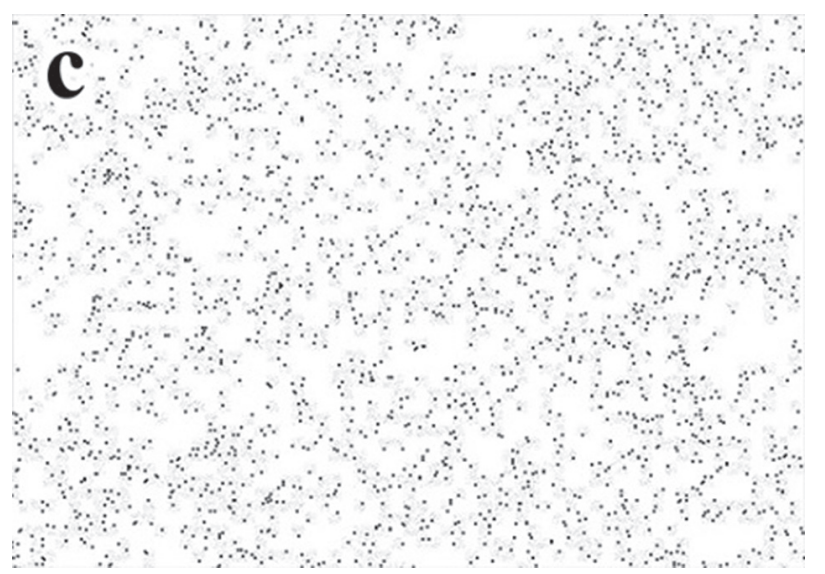

c) Magnesium

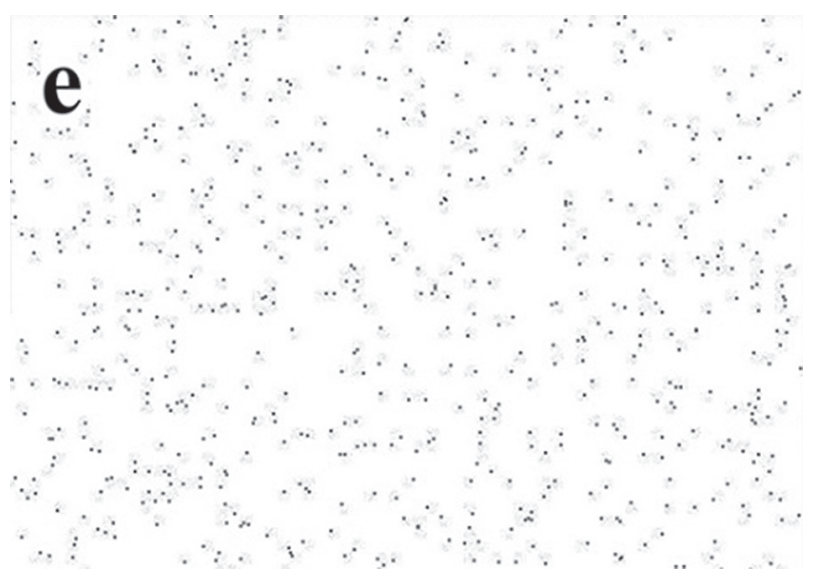

e) Lanthanum

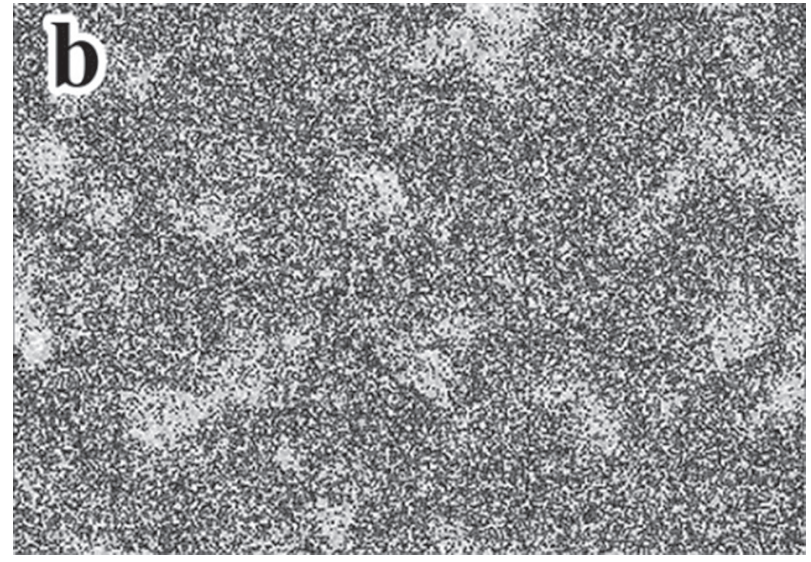

b) Aluminium

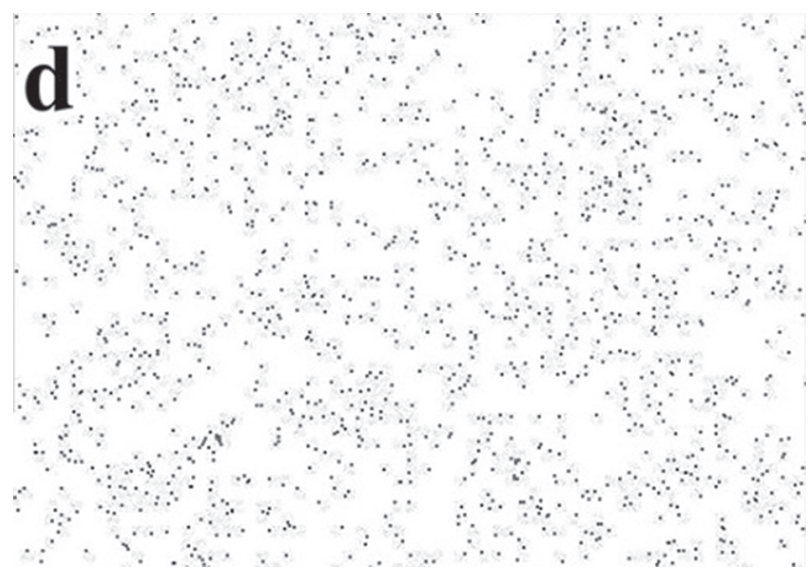

d) Yttrium

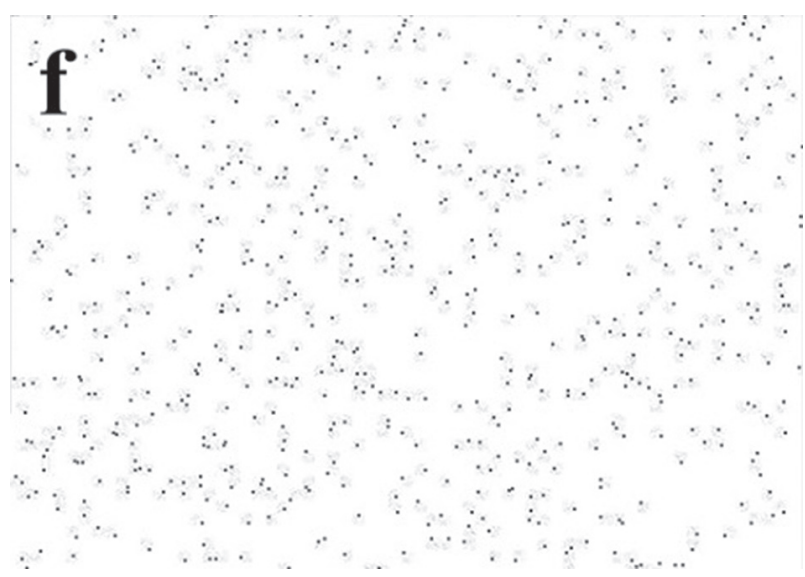

f) Cerium

Figure 5. SEM micrograph of the deposit after sintering (a), results of X-ray mapping showing the presence of Aluminium (b), Magnesium (c), Yttrium (d), Lanthanum (e) and Cerium (f), in the sample showing adsorption of cations in surface of deposited powder. 
inhomogeneous packing of the particles was observed after sintering. 2070351 have sufficient rate and density but unfavorable pore size distribution. Fracture surface of this sample shown in Figure 4d. inhomogeneity in pore and grain sizes indicated that although good green density, sintering step leads to inhomogeneity in sintered sample. Other images i.e. Figure $4 \mathrm{a}$, e and $\mathrm{f}$ have similar packing density and pore size with slightly differences in grain size. It must be note that there is a similar packing density along the thickness of the different samples and along their lateral dimensions.

\section{Doping and cation distribution}

SEM image of the samples with X-Ray mapping analysis are used to investigate the elemental composition, which is shown in Figure 5. The appearance of the $\mathrm{Mg}, \mathrm{Y}$, $\mathrm{La}$ and $\mathrm{Ce}$ confirms the presence of these cations in the deposition with alumina that shows absorption of these elements with iodine on surface of powder in suspension, while the low intensity of the dots is due to the small amount of it in suspension. No appreciable differences were observed among the grains and grain boundaries shown no segregation of these cations observed after sintering.

\section{CONCLUSIONS}

The present work is among first reports on systematic evaluation of the important process parameters that simultaneously investigate density, weight and efficiency for electrophoretic deposition process and sintering by SPS. This methodology can probably be extended to other responses of EPD process such as current density of deposit cell. The following are some of the observations from the present work:

In addition to weight of deposited, density and efficiency, pore size distribution can be affected by EPD variables. Best pore size distribution achieved in low rate deposition conditions and dilute suspension. Narrow pore size distribution and sharp slop in $\mathrm{d}_{50}$ produce high density alumina samples in $2 \mathrm{~h}$ at $1450^{\circ} \mathrm{C}$ sintering temperature.

EPD could shape a green bodies with cation dopant to be used in pressure less sintering method and controlling the grain growth.

Acknowledgments

The authors would like to acknowledge the Iranian Research Organization for Science and Technology (IROST) for providing research facilities.

\section{REFERENCES}

1. Roh J.Y., Kwon J., Lee C.S., Choi J.S. (2011): Novel fabrication of pressure-less sintering of translucent powder injection molded (PIM) alumina blocks. Ceramics International, 37(1), 321-326. doi:10.1016/j.ceramint.2010. 09.011

2. Krell A., Blank P., Ma H., Hutzler T., Nebelung M. (2003): Processing of High-Density Submicrometer $\mathrm{Al}_{2} \mathrm{O}_{3}$ for New Applications. Journal of the American Ceramic Society, 86(4), 546-53. doi:10.1111/j.1151-2916.2003.tb03339.x

3. Zhu X.W., Sakka Y., Suzuki T.S., Uchikoshi T., Kikkawa S. (2010): The c-axis texturing of seeded $\mathrm{Si}_{3} \mathrm{~N}_{4}$ with $\beta-\mathrm{Si}_{3} \mathrm{~N}_{4}$ whiskers by slip casting in a rotating magnetic field. Acta Materialia, 58(1), 146-161. doi:10.1016/j.actamat. 2009.08.064

4. Chelluri B., Knoth E., Schumaker E., Franks L.P. (2010). Method for Producing SiC Armor Tiles of Higher Performance at Lower Cost. In: Swab JJ, Sanjaythur, Ohji T (eds.): Advances in Ceramic Armor VI: Ceramic Engineering and Science Proceedings. John Wiley \& Sons, Inc., Vol. 31 (5), pp 199-205.

5. Krell A., Klimke J. (2006): Effects of the Homogeneity of Particle Coordination on Solid-State Sintering of Transparent Alumina. Journal of the American Ceramic Society, 89(6), 1985-1992. doi:10.1111/j.1551-2916.2006.00985.x

6. Krell A., Blank P. (1995): Grain size dependence of hardness in dense submicrometer alumina. Journal of the American Ceramic Society, 78(4), 1118-1120. doi:10.1111/ j.1151-2916.1995.tb08452.x

7. Shan M., Mao X., Zhang J., Wang S. (2009): Electrophoretic shaping of sub-micron alumina in ethanol. Ceramics International, 35(5), 1855-1861. doi:10.1016/j.ceramint. 2008.10.033

8. Bredol M., Micior J., Klemme S. (2014): Electrophoretic deposition of alumina, yttria, yttrium aluminium garnet and lutetium aluminium garnet. Journal of Materials Science, 49(20), 6975-6985. doi:10.1007/s10853-014-8403-0

9. Braun A., Wolff M., Falk G., Clasen R. (2005). Transparent Alumina Ceramics with Sub-Microstructure by Means of Electrophoretic Deposition. in: Brito M.E., Filip P., Lewinsohn C., et al (eds.): Developments in Advanced Ceramics and Composites: A Collection of Papers Presented at the $29^{\text {th }}$ International Conference on Advanced Ceramics and Composites, Ceramic Engineering and Science Proceedings, John Wiley \& Sons, USA, Vol 26(8), pp 97-104.

10. Castro Y., Ferrari B., Moreno R., Duran A. (2004): Coatings produced by electrophoretic deposition from nano-particulate silica sol-gel suspensions. Surface and Coatings Technology, 182(2), 199-203. doi:10.1016/j. surfcoat.2003.07.001

11. Zhang Z., Huang Y., Jiang Z. (1994): Electrophoretic Deposition Forming of SiC-TZP Composites in a Nonaqueous Sol Media. Journal of the American Ceramic Society, 77(7), 1946-1949. doi:10.1111/j.1151-2916.1994. tb07075.x

12. Bernardo M.S., Malič B., Kuscer D. (2015): PZT-Based Thick Films Prepared by Electrophoretic Deposition from Suspensions with Different Alcohol-Based Solvents. Journal of The Electrochemical Society, 162(11), D3040-D3048. doi:10.1149/2.0151511jes 
13. Besra L., Liu M. (2007): A review on fundamentals and applications of electrophoretic deposition (EPD). Progress in materials science, 52(1), 1-61. doi:10.1016/j.pmatsci. 2006.07.001

14. Ma J., Cheng W. (2002): Deposition and packing study of sub-micron PZT ceramics using electrophoretic deposition. Materials Letters, 56(5), 721-727. doi:10.1016/S0167577X(02)00602-X

15. Farrokhi-Rad M., Shahrabi T., Khanmohammadi S. (2014): Electrophoretic deposition of titania nanoparticles: Wet density of deposits during EPD. Bulletin of Materials Science, 37(5), 1039-1046. doi:10.1007/s12034-014-00421

16. Ji C., Lan W., Xiao P. (2008): Fabrication of YttriaStabilized Zirconia Coatings Using Electrophoretic Depo- sition: Packing Mechanism During Deposition. Journal of the American Ceramic Society, 91(4), 1102-1109. doi:10.1111/j.1551-2916.2008.02261.x

17. Krueger H.G., Knote A., Schindler U., Kern H., Boccaccini A.R. (2004): Composite ceramic-metal coatings by means of combined electrophoretic deposition and galvanic methods. Journal of materials science, 39(3), 839-844. doi:10.1023/B:JMSC.0000012912.96350.d2

18. Hamaker H.C. (1940): Formation of a deposit by electrophoresis. Transactions of the Faraday Society, 35, 279-287. doi:10.1039/TF9403500279

19. Hsueh C.H., Evans A.G., Coble R.L. (1982): Microstructure development during final/intermediate stage sintering - I. Pore/grain boundary separation. Acta Metallurgica, 30(7), 1269-1279.doi:10.1016/0001-6160(82)90145-6 